\title{
Leaf Morphogenesis: Insights From the Moss Physcomitrium patens
}

\author{
Wenye Lin ${ }^{1}$, Ying Wang ${ }^{2}$, Yoan Coudert ${ }^{3}$ and Daniel Kierzkowski ${ }^{*}$ \\ ${ }^{1}$ IRBV, Department of Biological Sciences, University of Montréal, Montréal, Montréal, QC, Canada, ${ }^{2}$ College of Life \\ Sciences, University of Chinese Academy of Sciences, Beijing, China, ${ }^{3}$ Laboratoire Reproduction et Développement des \\ Plantes, Ecole Normale Supérieure de Lyon, CNRS, INRA, Université Claude Bernard Lyon 1, INRIA, Lyon, France
}

Specialized photosynthetic organs have appeared several times independently during the evolution of land plants. Phyllids, the leaf-like organs of bryophytes such as mosses or leafy liverworts, display a simple morphology, with a small number of cells and cell types and lack typical vascular tissue which contrasts greatly with flowering plants. Despite this, the leaf structures of these two plant types share many morphological characteristics. In this review, we summarize the current understanding of leaf morphogenesis in the model moss Physcomitrium patens, focusing on the underlying cellular patterns and molecular regulatory mechanisms. We discuss this knowledge in an evolutionary context and identify parallels between moss and flowering plant leaf development. Finally, we propose potential research directions that may help to answer fundamental questions in plant development using moss leaves as a model system.

OPEN ACCESS

Edited by:

Enrico Scarpella,

University of Alberta, Canada

Reviewed by:

Jill Harrison,

University of Bristol, United Kingdom Charlotte Kirchhelle,

University of Oxford, United Kingdom

*Correspondence:

Daniel Kierzkowski

daniel.kierzkowski@umontreal.ca

Specialty section:

This article was submitted to Plant Development and EvoDevo,

a section of the journal

Frontiers in Plant Science

Received: 04 July 2021 Accepted: 02 September 2021 Published: 23 September 2021

Citation:

Lin W, Wang Y, Coudert $Y$ and Kierzkowski D (2021) Leaf Morphogenesis: Insights From the Moss Physcomitrium patens.

Front. Plant Sci. 12:736212.

doi: 10.3389/fpls.2021.736212
Keywords: Physcomitrum patens, Physcomitrella patens, leaf, heteroblasty, bryophytes, development, organogenesis, cellular dynamics

\section{INTRODUCTION}

Leaves are photosynthetic organs with mainly determinate growth that evolved several times independently during land plant diversification (Tomescu, 2009; Nelissen et al., 2016). These organs can be large with a complex structure as some flowering plant leaves, or small and anatomically simple as bryophyte phyllids (hereafter called leaves). However, they all display a predominantly flat shape as an adaptation to optimize light capture. The genetic basis of leaf development has been extensively studied in flowering plants (Bar and Ori, 2015; Du et al., 2018; Maugarny-Calès and Laufs, 2018). However, how genetic commands are coordinated between cells and translated into supracellular level organization, and the final leaf shape remains largely elusive. This is due to the complex, multilayer structure of flowering plant leaves with interweaving interactions between cells and tissues (Malinowski, 2013).

The development of upright bryophyte gametophores, or leafy shoots, has contributed to the colonization of new environments by plants and helped mosses to thrive on land for hundreds of million years (Mitchell et al., 2021). Moss leaves are lateral appendages attached to the stem of gametophores. In the model species P. patens (Physcomitrum patens, formerly known as Physcomitrella patens), leaves are small and composed of cells arranged principally in a single layer (Courtice and Cove, 1983; Figures 1A-C). As the gametophore grows, leaves start to develop a midrib (a bundle of specialized conducting cells) and marginal serrations (Sakakibara et al., 2003; Barker and Ashton, 2013; Dennis et al., 2019; Figure 1E). At first glance, the lanceolate-shaped leaves of $P$. patens mirror the dominant leaf shape of flowering plants, but they have a much simpler structure and smaller size, and can be more easily imaged, which makes them an ideal 


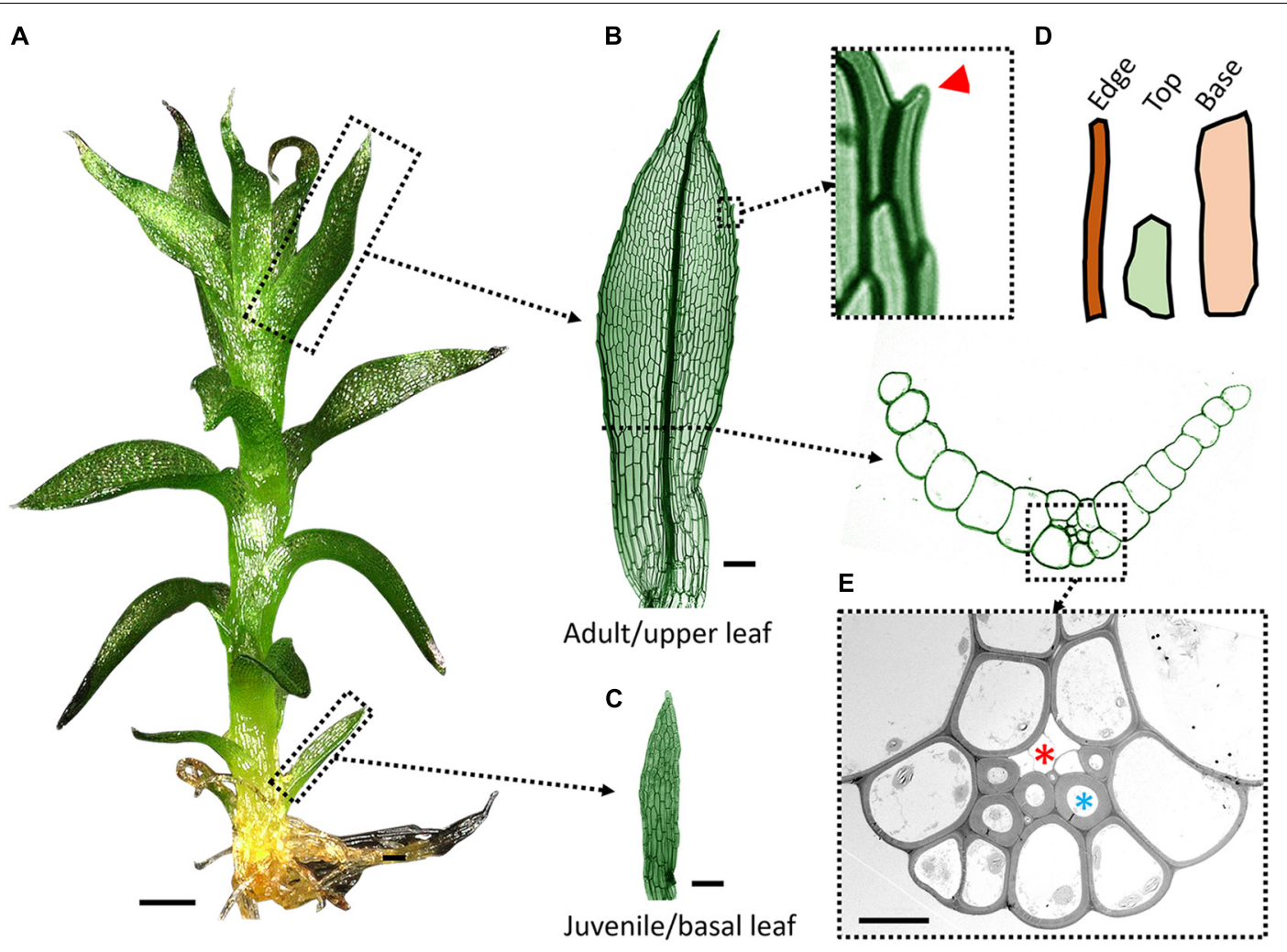

FIGURE 1 | Leaf anatomy in P. patens. (A) A leafy shoot (or gametophore) with juvenile and adult leaves from the base to the top. (B) Adult (upper) leaf has a multicellular midrib and lanceolate shape. The leaf margin is magnified to show marginal serrations (red arrowhead) formed by cell tip outgrowths. (C) First juvenile leaf is composed of a single cell layer and has a rectangular shape. (D) Three cell shapes are commonly identified in adult leaves: long and narrow cells on the edge; smaller and more isodiametric cells close to the tip (top); long and broad cells near the base (based on Dennis et al., 2019). (E) TEM cross-section image of a midrib cell bundle with thick-walled stereids and thin-walled hydroids (marked with blue and red asterisk respectively). Scale bars: $200 \mu \mathrm{m}$ in (A); $50 \mu \mathrm{m}$ in (B,C); and $10 \mu \mathrm{m}$ in (E).

system for studying leaf development. However, our understanding of moss leaf organogenesis is still limited. Here, we review current knowledge on $P$. patens leaf organogenesis, focusing on the cellular dynamics and molecular factors underlying leaf development.

\section{LEAF INITIATION}

In contrast to flowering plants where lateral organs are generated at the multicellular shoot apical meristem (Kuhlemeier, 2017), leaves in bryophytes are derived from a single shoot apical cell (Gifford, 1983; Harrison et al., 2009). This shoot apical cell is itself generated from a single shoot initial cell. Specification of the shoot initial cell requires both cytokinin and auxin (Ashton et al., 1978; Cove et al., 2006; Bennett et al., 2014). Factors including DEFECTIVE KERNEL 1 (DEK1), NO GAMETOPHORES 1 and 2 (NOG1 and 2) RECEPTOR-LIKE PROTEIN KINASE 2 (RPK2), and CLAVATA (CLV) function through APETALA2-type (AP2type) transcription factors to control the frequency of shoot initial cells (Aoyama et al., 2012; Perroud et al., 2014; Moody et al., 2018, 2021; Whitewoods et al., 2018; Demko et al., 2021; Nemec Venza et al., 2021). In P. patens, a shoot initial cell undergoes several rounds of stereotypic, oblique cell divisions that lead to the formation of a tetrahedral shoot apical cell, marking the transition from a so-called $2 \mathrm{D}$ to $3 \mathrm{D}$ growth mode (Figure 2A; Harrison et al., 2009). These divisions are also regulated by DEK1, CLV, NOG1, and NOG2 genes (Perroud et al., 2014; Moody et al., 2018, 2021; Whitewoods et al., 2018; Nemec Venza et al., 2021), and precisely fulfilled by mitotic spindle orientation regulators, including microtubule-associated protein TARGETING FACTOR FOR Xklp2 and SABRE (Kosetsu et al., 2017; Kozgunova et al., 2020; Cheng and Bezanilla, 2021). Additionally, SOSEKI proteins might also be involved in apical cell identity specification and division (van Dop et al., 2020).

The self-renewing activity of the shoot apical cell gives the gametophytic leafy shoot a capacity for indeterminate growth. Through successive asymmetric divisions, the apical cell maintains itself and gives rise to merophytes, which divide to generate leaf initials and cells that produce stem tissues (Figure 2A). This cell-autonomous capacity to rotate cell division planes in $3 \mathrm{D}$ initiates the growth of upright leafy gametophores and underlies its spiral phyllotaxy (Figure 2B; Kamamoto et al., 2021; Véron et al., 2021). Similar to flowering plant meristems, leaf initial outgrowth and shoot apical cell function in mosses involve auxin and PIN-FORMED (PIN) mediated auxin 
A

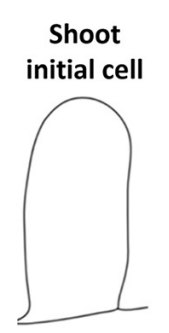

Shoot apical cell

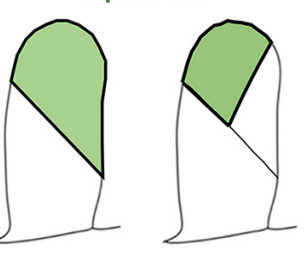

Side view
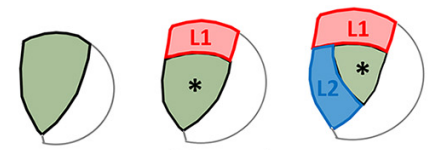

Top view
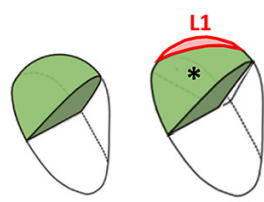

Side view
B

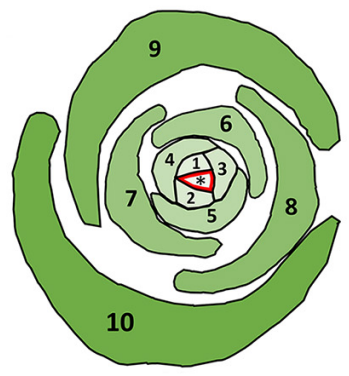

。

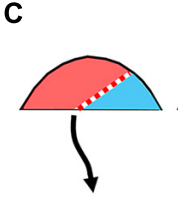

D

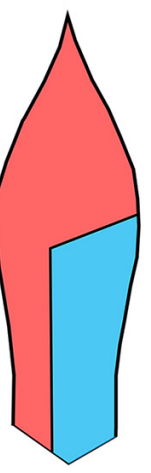

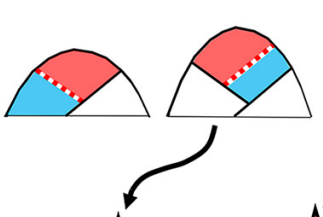
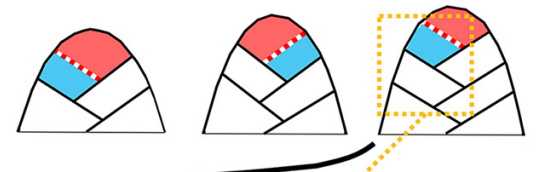

$F$

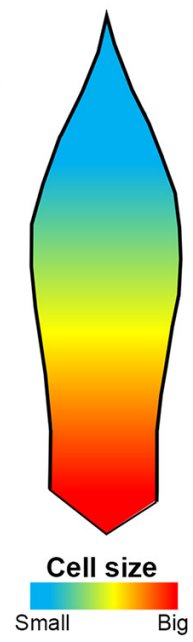

G

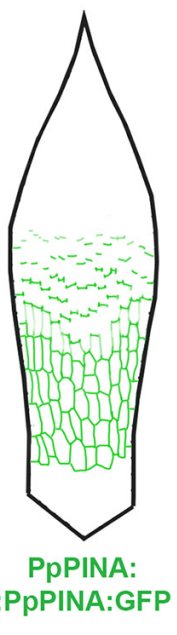

FIGURE 2 | Leaf growth in P. patens. (A) Schematic representation of the transition from 2D to 3D growth during leafy gametophore initiation. Gametophore shoot initial cell divides obliquely to generate the shoot apical cell (in green). Second and third divisions of the shoot initial cell are also oblique and generate a hair cell (in white) and the first leaf initial ( $\mathrm{L} 1$, in red) consecutively. From this stage, the shoot apical initial cell becomes tetrahedral and generates subsequent leaf initials. (B) A single apical cell (marked with asterisk) produces leaves in a spiral phyllotactic pattern with leaf sequences indicated in consecutive numbers. (C) Schematic representation of the early development of the juvenile leaf. The leaf apical cell is shown in red and the cell recently cleaved from the apical cell is shown in blue. Red dotted lines indicate recent cell division (based on Harrison et al., 2009). (D) Schematic representation of clonal sectors arising from single cells shown in (C) at early stages of leaf development. (E) Schematic representation of cell division patterns within the segments generated by the leaf apical cell. Red lines represent new walls (based on Harrison et al., 2009). (F) Schematic representation of the distribution of cell sizes in the adult leaf. Bigger cells are located in the distal region of the leaf, smaller cells in proximal region (based on Dennis et al., 2019). (G) Schematic representation of the PpPINA protein localization (in green) in the adult leaf (Viaene et al., 2014).

transport but the precise mechanism of their action is unclear (Bennett et al., 2014). SHORT-LEAF (SHLF), a bryophyte specific tandem direct repeat gene, is likely involved in the underlying mechanism, as SHLF expression is associated with auxin accumulation in the gametophore and the capacity of the shoot apical cell to generate leaves (Mohanasundaram et al., 2021).

\section{LEAF DEVELOPMENT}

Leaf development in $P$. patens starts with the outgrowth of the leaf initial cell, which depends on auxin and cellulose biosynthesis (Goss et al., 2012; Bennett et al., 2014). The leaf initial cell maintains meristematic potential and cleaves daughter cells basipetally (Harrison et al., 2009). Similar to the shoot apical cell, the divisions of the leaf initial cell seem to be controlled cell-autonomously but instead of rotating spirally, subsequent divisions alternate in the same plane and are almost perpendicular to each other (Figures 2C,D; Harrison et al., 2009; Bascom et al., 2016). The orientation of the leaf initial cell division plane is likely controlled by microtubules as mutants lacking the cortical microtubule regulator TONNEAU1 develop thick multi-layered leaves (Spinner et al., 2010). Eventually, the leaf apical cell stops dividing and becomes the pointed tip of the leaf. Daughter cells derived from the leaf apical cell divide further, first near the leaf base (Figure 2E). The proliferative activity of these daughter cells decreases gradually so that cells near the tip divide less frequently and give rise to smaller segments of the leaf (Figures 2C,D; Harrison et al., 2009). Several rounds of longitudinal divisions within sectors derived from the leaf apical cell, especially in the outermost lateral portion of the leaf, lead to leaf broadening (Figure 2E). Additional transverse 
divisions also contribute to extending the daughter segments in the proximo-distal axis (Figure 2E; Harrison et al., 2009).

Quantitative analysis of the entire leaf growth at cellular resolution has not yet been performed in $P$. patens. However, the basipetal gradient of cell proliferation (Figure 2E; Harrison et al., 2009) and basipetal increase of cell sizes in mature leaves (Figure 2F; Barker and Ashton, 2013; Dennis et al., 2019) indicate that cells near the leaf tip are the earliest to cease growth. Cells at the tip differentiate first as they become insensitive to exogenous cytokinin, while cell proliferation in more proximal leaf regions is stimulated by this hormone (Barker and Ashton, 2013). Interestingly, basipetal gradients of growth, proliferation, and differentiation are key features of many flowering plant leaves and is controlled non-cell-autonomously by positional information (Avery, 1933; Andriankaja et al., 2012; Kuchen et al., 2012; Fox et al., 2018; Kierzkowski et al., 2019). Thus, apart from the cell-autonomous behavior of the leaf apical cell, positional cues also likely play a role in controlling moss leaf growth.

Auxin is a fundamental player in plant organogenesis where it regulates cell proliferation, elongation, and differentiation in a positional and context dependent manner (Vieten et al., 2007; Weijers et al., 2018). An essential common genetic toolbox involved in auxin biosynthesis, transport, and signaling is conserved between flowering plants and bryophytes (Poli et al., 2003; Kato et al., 2018; Thelander et al., 2018). Auxin could provide positional information during moss leaf development. Although the signal of the GH3:GUS reporter has not been observed in the wild type leaves of $P$. patens, exogenous auxin treatments disrupt leaf growth (Barker and Ashton, 2013; Bennett et al., 2014).

Auxin distribution within the developing leaf could be controlled by canonical auxin efflux carriers PIN-FORMED A and B (PpPINA and B) (Bennett et al., 2014; Viaene et al., 2014). The expression of PPPINA is displaced along the proximo-distal axis of the leaf during growth and correlates with developmental gradients (Figure 2G). This correlation is also evident at the subcellular level, where PpPINA protein is localized bipolarly on both apical and basal cell sides close to the leaf tip, while it is distributed more uniformly in cell membranes near the leaf base (Figure 2G; Viaene et al., 2014). Alternatively, auxin gradients in mosses might also be achieved by callosecontrolled plasmodesmata-mediated diffusion (Coudert et al., 2015). Gametophores of the shlf mutant produce shorter leaves with a decreased cell number, similar to plants grown with a high auxin concentration or overexpressing PpPINA. Auxin activity gradients can be detected in leaves of the shlf mutant where GH3:GUS signal is present in very young leaves and at the tip of more developed leaves (Mohanasundaram et al., 2021). As SHLF might regulate plasmodesmata frequency, it could control leaf morphogenesis through the regulation of auxin gradients (Mohanasundaram et al., 2021).

Class III Homeodomain-Leucine Zipper (HD-ZIP III) transcription factors are key players during flowering plant development and are associated with auxin synthesis and transport (Prigge and Clark, 2006; Ariel et al., 2007; Turchi et al., 2015). There are five HD-ZIP III homologs in the P. patens, namely $P p C 3 H D Z 1-5$ (Yip et al., 2016). $P p C 3 H D Z$ expression colocalizes with actively developing regions in adult leaves. Strikingly, $P p C 3 H D Z$ knock-down induces pronounced, multicellular protrusions along leaf margins that resemble the distal portion of wild-type leaves. It indicates that in $P p C 3 H D Z$ knock-down plants, daughter cells derived from the leaf apical cell, whose normal divisions produce characteristic leaf sectors (Figures 2C,D), could recapitulate the cell-autonomous behavior of the apical cell itself. Additionally, in $P p C 3 H D Z$ knock-down leaves, cell number is reduced, suggesting that HD-ZIP III genes are important for the establishment and/or the maintenance of the proliferative activity of the daughter cells (Yip et al., 2016). PpC3HDZ expression domain mirrors PpPINA distribution, and both $P p C 3 H D Z$ knock-down and $P p P I N A / P p P I N B$ knock-out lines produce narrower leaves with a reduced cell number, indicating that HD-ZIP III function could be at least partially related to auxin-dependent positional information (Bennett et al., 2014; Viaene et al., 2014; Yip et al., 2016).

\section{LEAF HETEROBLASTIC DEVELOPMENT}

Although all leaves of $P$. patens initiate from single cells, their morphology changes gradually up the gametophore axis (Figure 1A; Barker and Ashton, 2013; Dennis et al., 2019), a phenomenon called heteroblastic development (Zotz et al., 2011). As in Arabidopsis, juvenile leaves in P. patens are much smaller than adult leaves (Figures 1B,C; Courtice and Cove, 1983; Barker and Ashton, 2013). The width of the juvenile leaf is relatively constant except at the tapering tip, resulting in a roughly oblong shape (Figure $\mathbf{1 C}$ ). By contrast, adult leaves have a lanceolate shape with a narrow base, a broader middle part, and a pointy tip (Figure 1B). The increase in size during heteroblastic development results from an increase in cell number but not cell size (Dennis et al., 2019). In flowering plants, auxin and cytokinin regulate cell proliferation and differentiation in an opposite manner during leaf development (Shani et al., 2010; Kierzkowski et al., 2019; Skalák et al., 2019). Exogenous treatments with auxin, or knock-out mutants in auxin efflux carriers PPPINA and $P p P I N B$, cause a decrease in moss leaf size by reducing cell number (Bennett et al., 2014; Viaene et al., 2014). By contrast, cytokinin treatment increases cell proliferation and enhances adult leaf characteristics (Barker and Ashton, 2013). Altogether this indicates an important role of cytokinin-auxin cross-talk in moss leaf heteroblastic development.

The transition from juvenile to adult leaves in $P$. patens is also associated with morphological changes of the marginal cells that become long and narrow (Figure 1D) as well as the formation of a multilayered midrib (Figure 1E; Barker and Ashton, 2013; Dennis et al., 2019). Marginal cells tend to grow slightly outward at their distal end to form marginal serrations that usually appear on the apical half of the adult leaf (Barker and Ashton, 2013). The leaf margin in flowering plants has a distinct cell morphology and plays an important role during leaf development (Bilsborough et al., 2011; Nakata et al., 2012; Kalve et al., 2014; Alvarez et al., 2016; Hayakawa et al., 2016). Marginal cells in $P$. patens could play a role in controlling upper 
leaf size and shape by restricting or promoting growth around its circumference. The wrinkled leaves with undifferentiated marginal cells of crinkly4 mutants likely result from mechanical conflicts in lamina cells (Demko et al., 2016). The leaf margin could also work in tandem with the midrib in the bigger leaves and ensure proper leaf flattening by preventing blade twisting. However, the role of marginal cells in moss leaf morphogenesis remains elusive.

\section{THE ROLE OF MIDRIB}

Unlike vascular plants which conduct water through the xylem, mosses neither possess vessel elements or tracheids, nor have an interconnected network of veins. Instead, mosses mostly rely on external water conduction by capillary action to carry out water-dependent physiological functions (Proctor, 1979). However, the adult leaves conduct water through a multilayered tissue called the midrib that is reminiscent of a vascular bundle and arises through a series of periclinal and anticlinal cell divisions (Ligrone et al., 2000; Sakakibara et al., 2003; Yip et al., 2016). These cell divisions give rise to different cell types within the leaf midrib, including thick-walled stereids and thin-walled, elongated hydroids (Figure 1E). Hydroids are the main water-conducting cells. They are initially alive, before undergoing programmed cell death, and have fully degenerate protoplasm upon maturation (Xu et al., 2014). Stereids also undergo programmed cell death but may mainly serve a supporting purpose. Therefore, hydroids resemble xylem vessel elements and tracheids, except that they lack a lignified secondary cell wall, while stereids resemble xylem fiber cells (Ligrone et al., 2000).

Several genes affecting midrib formation have been identified and characterized. For instance, among the seven moss genes that encode $V N D / N S T / S N D$ family transcription factors, six of them ( $P p V N S 1-7$, except $P p V N S 3$ ) are expressed in the central region of newly formed leaves or in developing midribs. The triple mutant ( $p$ pvns $1,6,7)$ forms morphologically normal midribs. However, stereid programmed cell death and hydroid proliferation are disrupted, and the water conducting capacity is greatly compromised (Xu et al., 2014). Interestingly, VNS orthologs are critical for xylem vessel element formation in angiosperms, suggesting that mosses and vascular plants may at least partly use the same molecular mechanism in shaping water-conducting tissue. The leaves of midrib-defective mutants tend to curl around the middle axis under low-humidity conditions, indicating a water transport deficiency. Nevertheless, compromised midrib formation does not seem to have a detrimental impact on overall moss growth, at least in laboratory conditions.

HD-ZIP III transcription factors also control midrib establishment. When their function is suppressed, midrib formation is abnormal and leaf shape becomes distorted (Yip et al., 2016). Given that HD-ZIP III transcription factors ATHB8, ATHB15, and REVOLUTA are essential for procambial cell specification and vasculature development, the observation that HD-ZIP III proteins function in specifying moss waterconducting tissues further suggests that shared molecular mechanisms underpin conducting tissue development in convergent plant organs (Kang and Dengler, 2002; Ohashi-Ito et al., 2002; Green et al., 2005; Prigge et al., 2005; Donner et al., 2009) and therefore that these mechanisms may have evolved before the divergence between bryophytes and vascular plants. Nonetheless, further research on midrib development is needed to uncover the regulatory circuits underlying the morphological differences between juvenile and adult leaves.

\section{PERSPECTIVES}

In this review, we summarized the current understanding of leaf development in the model species $P$. patens. Proper leaf morphogenesis in this moss seems to require coordination of cellautonomous and non-cell-autonomous developmental processes that are controlled via cross-talks between molecular regulators that are bryophyte-specific or shared by land plants. It is, however, still difficult to understand how these genetic and hormonal inputs are translated into cellular growth and division patterns and how they are coordinated in space and time within the mechanically connected tissue constituting the P. patens leaf.

In recent years, new research approaches combining genetics, quantitative live-imaging, biomechanics, and computational modeling have massively advanced our understanding of organ development in plants (Hervieux et al., 2016; Solly et al., 2017; Fox et al., 2018; Hong et al., 2018; Kierzkowski et al., 2019; Sapala et al., 2019; Wolny et al., 2020; Whitewoods et al., 2020; Hernandez-Lagana et al., 2021; Vijayan et al., 2021). The next step will be to apply such a multidisciplinary approach to study moss leaf development.

In comparison with the complex anatomy of flowering plant leaves, the single-cell-layered structure of $P$. patens leaf provides a unique opportunity to quantify the development of the entire organ in 3D. Such an approach, should provide a comprehensive picture of moss leaf developmental dynamics at cellular resolution that otherwise would be difficult to apprehend. In contrast with flowering plants, gene targeting by homologous recombination is very efficient in $P$. patens, and together with CRISPR/Cas9-mediated gene editing, permits to bypass genetic redundancy and rapidly generate highorder mutants (Koshimizu et al., 2018). Combination of imaging and genetic approaches will, for example, help us to understand the precise role of molecular regulators in the control of cell-autonomous and non-cell-autonomous behaviors during growth and their role in juvenile to adult leaf transition.

Single-cell-layered leaves in $P$. patens will also be a huge asset to dissect the role of biomechanical signals regulating plant organogenesis. Largely eliminating complex interactions that occur between different tissue layers of developing organs, as in flowering plants, this moss model system should provide a better understanding of the mechanical interactions between individual cells and their role in the coordination of organ growth. As $P$. patens leaves are easy to manipulate and have relatively 
big cells, they should also enable precise measurements of cell mechanical properties using modern micro-indentation devices (Routier-Kierzkowska et al., 2012; Robinson et al., 2017; Majda et al., 2019) or turgor pressure manipulations (Kierzkowski et al., 2012; Sapala and Smith, 2020). All these experimental inputs, in combination with geometrically accurate templates extracted from confocal images, will enable the creation of biologically realistic simulations of the entire moss leaf. Such models will not only provide a comprehensive picture of $P$. patens leaf development, but also advance our general understanding of the mechanism governing plant organogenesis.

\section{AUTHOR CONTRIBUTIONS}

WL, YW, YC, and DK wrote and edited the article. All authors contributed to the article and approved the submitted version.

\section{REFERENCES}

Alvarez, J. P., Furumizu, C., Efroni, I., Eshed, Y., and Bowman, J. L. (2016). Active suppression of a leaf meristem orchestrates determinate leaf growth. Elife 5:e15023. doi: 10.7554/eLife.15023

Andriankaja, M., Dhondt, S., De Bodt, S., Vanhaeren, H., Coppens, F., De Milde, L., et al. (2012). Exit from proliferation during leaf development in Arabidopsis thaliana: a not-so-gradual process. Dev. Cell 22, 64-78. doi: 10.1016/j.devcel. 2011.11.011

Aoyama, T., Hiwatashi, Y., Shigyo, M., Kofuji, R., Kubo, M., Ito, M., et al. (2012). AP2-type transcription factors determine stem cell identity in the moss Physcomitrella patens. Development 139, 3120-3129. doi: 10.1242/dev.076091

Ariel, F. D., Manavella, P. A., Dezar, C. A., and Chan, R. L. (2007). The true story of the HD-Zip family. Trends Plant Sci. 12, 419-426. doi: 10.1016/j.tplants.2007. 08.003

Ashton, N. W., Grimsley, N. H., and Cove, D. J. (1978). Analysis of Gametophytic Development in the Moss, Physcomitrella patens, Using Auxin and Cytokinin Resistant Mutants. Planta 144, 427-435. doi: 10.1007/bf00380118

Avery, G. S. Jr. (1933). STRUCTURE AND DEVELOPMENT OF THE TOBACCO LEAF. Am. J. Bot. 20, 565-592. doi: 10.1002/j.1537-2197.1933.tb08913.x

Bar, M., and Ori, N. (2015). Compound leaf development in model plant species. Curr. Opin. Plant Biol. 23, 61-69. doi: 10.1016/j.pbi.2014.10.007

Barker, E. I., and Ashton, N. W. (2013). Heteroblasty in the moss, Aphanoregma patens (Physcomitrella patens), results from progressive modulation of a single fundamental leaf developmental programme. J. Bryol. 35, 185-196. doi: 10. 1179/1743282013Y.0000000058

Bascom, C. S., Wu, S. Z., Nelson, K., Oakey, J., and Bezanilla, M. (2016). Longterm growth of moss in microfluidic devices enables subcellular studies in development. Plant Physiol. 172, 28-37. doi: 10.1104/pp.16.00879

Bennett, T. A., Liu, M. M., Aoyama, T., Bierfreund, N. M., Braun, M., Coudert, Y., et al. (2014). Plasma Membrane-Targeted PIN Proteins Drive Shoot Development in a Moss. Curr. Biol. 24, 2776-2785. doi: 10.1016/j.cub.2014.09. 054

Bilsborough, G. D., Runions, A., Barkoulas, M., Jenkins, H. W., Hasson, A., Galinha, C., et al. (2011). Model for the regulation of \&lt;em\&gt;Arabidopsis thaliana\&lt;/em\&gt; leaf margin development. Proc. Natl. Acad. Sci. 108, 3424L3429. doi: 10.1073/pnas.1015162108

Cheng, X., and Bezanilla, M. (2021). SABRE populates ER domains essential for cell plate maturation and cell expansion influencing cell and tissue patterning. Elife 10:e65166. doi: 10.7554/eLife.65166

Coudert, Y., Palubicki, W., Ljung, K., Novak, O., Leyser, O., and Harrison, C. J. (2015). Three ancient hormonal cues co-ordinate shoot branching in a moss. Elife 4:06808. doi: 10.7554/eLife.06808

Courtice, G. R. M., and Cove, D. J. (1983). Mutants of the moss Physcomitrella patens which produce leaves of altered morphology. J. Bryol. 12, 595-609. doi: 10.1179/jbr.1983.12.4.595

\section{FUNDING}

This work was supported by the 2020-NC-267497 grant from Fond de Recherche du Québec Nature et Technologies and Discovery grant RGPIN-2018-04897 from the Natural Sciences and Engineering Research Council of Canada to DK. This work was also supported by the grant 31871245 from National Natural Science Foundation of China (NSFC) and the grant 2019YFA0903902 from National Key R\&D Program of China (NKP) to YW.

\section{ACKNOWLEDGMENTS}

We thank Viraj Alimchandani and Andrea Gómez Felipe for critical reading of the manuscript. We also thank reviewers for their suggestions to improve the manuscript.

Cove, D., Bezanilla, M., Harries, P., and Quatrano, R. (2006). Mosses as model systems for the study of metabolism and development. Annu. Rev. Plant Biol. 57, 497-520. doi: 10.1146/annurev.arplant.57.032905.105338

Demko, V., Ako, E., Perroud, P.-F., Quatrano, R., and Olsen, O.-A. (2016). The phenotype of the CRINKLY4 deletion mutant of Physcomitrella patens suggests a broad role in developmental regulation in early land plants. Planta 244, 275-284. doi: 10.1007/s00425-016-2526-2

Demko, V., Belova, T., Messerer, M., Hvidsten, T. R., Perroud, P.-F., Mayer, K. F. X., et al. (2021). Calpain DEK1 acts as a developmental switch gatekeeping cell fate transitions. bioRxiv [Preprint]. doi: 10.1101/2021.08.25.457637

Dennis, R. J., Whitewoods, C. D., and Harrison, C. J. (2019). Quantitative methods in like-for-like comparative analyses of Aphanorrhegma (Physcomitrella) patens phyllid development. J. Bryol. 41, 314-321. doi: 10.1080/03736687.2019. 1668109

Donner, T. J., Sherr, I., and Scarpella, E. (2009). Regulation of preprocambial cell state acquisition by auxin signaling in Arabidopsis leaves. Development 136, 3235-3246. doi: 10.1242/dev.037028

Du, F., Guan, C., and Jiao, Y. (2018). Molecular Mechanisms of Leaf Morphogenesis. Mol. Plant 11, 1117-1134. doi: 10.1016/j.molp.2018.06.006

Fox, S., Southam, P., Pantin, F., Kennaway, R., Robinson, S., Castorina, G., et al. (2018). Spatiotemporal coordination of cell division and growth during organ morphogenesis. PLoS Biol. 16:e2005952. doi: 10.1371/journal.pbio.200 5952

Gifford, E. M. (1983). Concept of Apical Cells in Bryophytes and Pteridophytes. Annu. Rev. Plant Physiol. 34, 419-440. doi: 10.1146/annurev.pp.34.060183. 002223

Goss, C. A., Brockmann, D. J., Bushoven, J. T., and Roberts, A. W. (2012). A CELLULOSE SYNTHASE (CESA) gene essential for gametophore morphogenesis in the moss Physcomitrella patens. Planta 235, 1355-1367. doi: 10.1007/s00425-011-1579-5

Green, K. A., Prigge, M. J., Katzman, R. B., and Clark, S. E. (2005). CORONA, a member of the class III homeodomain leucine zipper gene family in Arabidopsis, regulates stem cell specification and organogenesis. Plant Cell 17, 691-704. doi: 10.1105/tpc.104.026179

Harrison, C. J., Roeder, A. H. K., Meyerowitz, E. M., and Langdale, J. A. (2009). Local Cues and Asymmetric Cell Divisions Underpin Body Plan Transitions in the Moss Physcomitrella patens. Curr. Biol. 19, 461-471. doi: 10.1016/j.cub. 2009.02.050

Hayakawa, Y., Tachikawa, M., and Mochizuki, A. (2016). Flat leaf formation realized by cell-division control and mutual recessive gene regulation. J. Theor. Biol. 404, 206-214. doi: 10.1016/j.jtbi.2016.06.005

Hernandez-Lagana, E., Mosca, G., Mendocilla-Sato, E., Pires, N., Frey, A., GiraldoFonseca, A., et al. (2021). Organ geometry channels reproductive cell fate in the Arabidopsis ovule primordium. Elife 10:e66031. doi: 10.7554/eLife.66031

Hervieux, N., Dumond, M., Sapala, A., Routier-Kierzkowska, A.-L., Kierzkowski, D., Roeder, A. H. K., et al. (2016). A Mechanical Feedback Restricts Sepal 
Growth and Shape in Arabidopsis. Curr. Biol. 26, 1019-1028. doi: 10.1016/j. cub.2016.03.004

Hong, L., Dumond, M., Zhu, M., Tsugawa, S., Li, C.-B., Boudaoud, A., et al. (2018). Heterogeneity and Robustness in Plant Morphogenesis: From Cells to Organs. Annu. Rev. Plant Biol. 69, 469-495. doi: 10.1146/annurev-arplant042817-040517

Kalve, S., De Vos, D., and Beemster, G. T. S. (2014). Leaf development: a cellular perspective. Front. Plant Sci. 5:362. doi: 10.3389/fpls.2014.00362

Kamamoto, N., Tano, T., Fujimoto, K., and Shimamura, M. (2021). Rotation angle of stem cell division plane controls spiral phyllotaxis in mosses. J. Plant Res. 134, 457-473. doi: 10.1007/s10265-021-01298-0

Kang, J., and Dengler, N. (2002). Cell cycling frequency and expression of the homeobox gene ATHB-8 during leaf vein development in Arabidopsis. Planta 216, 212-219. doi: 10.1007/s00425-002-0847-9

Kato, H., Nishihama, R., Weijers, D., and Kohchi, T. (2018). Evolution of nuclear auxin signaling: lessons from genetic studies with basal land plants. J. Exp. Bot. 69, 291-301. doi: 10.1093/jxb/erx267

Kierzkowski, D., Nakayama, N., Routier-Kierzkowska, A.-L., Weber, A., Bayer, E., Schorderet, M., et al. (2012). Elastic Domains Regulate Growth and Organogenesis in the Plant Shoot Apical Meristem. Science 335, 1096L-1099. doi: $10.1126 /$ science. 1213100

Kierzkowski, D., Runions, A., Vuolo, F., Strauss, S., Lymbouridou, R., RoutierKierzkowska, A.-L., et al. (2019). A Growth-Based Framework for Leaf Shape Development and Diversity. Cell 177, 1405.e-1418.e. doi: 10.1016/j.cell.2019. 05.011

Kosetsu, K., Murata, T., Yamada, M., Nishina, M., Boruc, J., Hasebe, M., et al. (2017). Cytoplasmic MTOCs control spindle orientation for asymmetric cell division in plants. Proc. Natl. Acad. Sci. 114, E8847L-E8854. doi: 10.1073/pnas. 1713925114

Koshimizu, S., Kofuji, R., Sasaki-Sekimoto, S., Kikkawa, M., Shimojima, M., Ohta, M., et al. (2018). Physcomitrella MADS-box genes regulate water supply and sperm movement for fertilization. Nat. Plants 4, 36-45. doi: 10.1038/s41477017-0082-9

Kozgunova, E., Yoshida, M. W., and Goshima, G. (2020). Spindle position dictates division site during asymmetric cell division in moss. bioRxiv [Preprint]. doi: 10.1101/2020.03.03.975557

Kuchen, E. E., Fox, S., de Reuille, P., Kennaway, R., Bensmihen, S., Avondo, J., et al. (2012). Generation of Leaf Shape Through Early Patterns of Growth and Tissue Polarity. Science 335, 1092-1096. doi: 10.1126/science.1214678

Kuhlemeier, C. (2017). Phyllotaxis. Curr. Biol. 27, R882-R887. doi: 10.1016/j.cub. 2017.05.069

Ligrone, R., Duckett, J. G., and Renzaglia, K. S. (2000). Conducting tissues and phyletic relationships of bryophytes. Philos. Trans. R. Soc. B Biol. Sci. 355, 795-813. doi: 10.1098/rstb.2000.0616

Majda, M., Sapala, A., Routier-Kierzkowska, A. L., and Smith, R. S. (2019). "Cellular Force Microscopy to Measure Mechanical Forces in Plant Cells," in Plant Cell Morphogenesis. Methods in Molecular Biology, Vol. 1992, eds F. Cvrčková and V. Žárský (New York, NY: Springer).

Malinowski, R. (2013). Understanding of Leaf Development-the Science of Complexity. Plants 2, 396-415. doi: 10.3390/plants2030396

Maugarny-Calès, A., and Laufs, P. (2018). Getting leaves into shape: a molecular, cellular, environmental and evolutionary view. Development 145:161646. doi: $10.1242 /$ dev. 161646

Mitchell, R., Strullu-Derrien, C., Sykes, D., Pressel, S., Duckett, J., and Kenrick, P. (2021). Cryptogamic ground covers as analogues for early terrestrial biospheres: Initiation and evolution of biologically mediated proto-soils. GeoBiology 19, 292-306. doi: 10.1111/gbi.12431

Mohanasundaram, B., Bhide, A. J., Palit, S., Chaturvedi, G., Lingwan, M., Masakapalli, S. K., et al. (2021). The unique bryophyte-specific repeatcontaining protein SHORT-LEAF regulates gametophore development in moss. Plant Physiol. 2021:kiab261. doi: 10.1093/plphys/kiab261

Moody, L. A., Kelly, S., Clayton, R., Weeks, Z., Emms, D. M., and Langdale, J. A. (2021). NO GAMETOPHORES 2 Is a Novel Regulator of the 2D to 3D Growth Transition in the Moss Physcomitrella patens. Curr. Biol. 31, 555.e-563.e. doi: 10.1016/j.cub.2020.10.077

Moody, L. A., Kelly, S., Rabbinowitsch, E., and Langdale, J. A. (2018). Genetic Regulation of the 2D to 3D Growth Transition in the Moss Physcomitrella patens. Curr. Biol. 28, 473.e-478.e. doi: 10.1016/j.cub.2017.12.052
Nakata, M., Matsumoto, N., Tsugeki, R., Rikirsch, E., Laux, T., and Okada, K. (2012). Roles of the Middle Domain-Specific WUSCHEL-RELATED HOMEOBOX Genes in Early Development of Leaves in Arabidopsis. Plant Cell 24, 519-535. doi: 10.1105/tpc.111.092858

Nelissen, H., Gonzalez, N., and Inzé, D. (2016). Leaf growth in dicots and monocots: so different yet so alike. Curr. Opin. Plant Biol. 33, 72-76. doi: 10.1016/j.pbi.2016.06.009

Nemec Venza, Z., Madden, C., Stewart, A., Liu, W., Novák, O., Pěnčík, A., et al. (2021). PpRPK2 modulates auxin homeostasis and transport to specify stem cell identity and plant shape in the moss Physcomitrella. bioRxiv, doi: 10.1101/ 2021.06.24.449551

Ohashi-Ito, K., Demura, T., and Fukuda, H. (2002). Promotion of transcript accumulation of novel Zinnia immature xylem-specific HD-Zip III homeobox genes by brassinosteroids. Plant Cell Physiol. 43, 1146-1153. doi: 10.1093/pcp/ pcf135

Perroud, P.-F., Demko, V., Johansen, W., Wilson, R. C., Olsen, O.-A., and Quatrano, R. S. (2014). Defective Kernel 1 (DEK1) is required for threedimensional growth in Physcomitrella patens. New Phytol. 203, 794-804. doi: $10.1111 / \mathrm{nph} .12844$

Poli, D., Jacobs, M., and Cooke, T. J. (2003). Auxin regulation of axial growth in bryophyte sporophytes: its potential significance for the evolution of early land plants. Am. J. Bot. 90, 1405-1415. doi: 10.3732/ajb.90.10.1405

Prigge, M. J., and Clark, S. E. (2006). Evolution of the class III HD-Zip gene family in land plants. Evol. Dev. 8, 350-361. doi: 10.1111/j.1525-142X.2006.00 107. $x$

Prigge, M. J., Otsuga, D., Alonso, J. M., Ecker, J. R., Drews, G. N., and Clark, S. E. (2005). Class III homeodomain-leucine zipper gene family members have overlapping, antagonistic, and distinct roles in Arabidopsis development. Plant Cell 17, 61-76. doi: 10.1105/tpc.104.026161

Proctor, M. C. F. (1979). "Structure and eco-physiological adaptation in bryophytes," in In Bryophyte systematics, Vol. 14, eds G. C. S. Clarke and J. G. Duckett (London: Academic Press), 479-509.

Robinson, S., Huflejt, M., Barbier, de Reuille, P., Braybrook, S., Schorederet, M., et al. (2017). An automated confocal micro-extensometer enables in vivo quantification of mechanical properties with cellular resolution. Plant Cell 29, 2959-2973. doi: 10.1105/tpc. 17.00753

Routier-Kierzkowska, A.-L., Weber, A., Kochova, P., Felekis, D., Nelson, B. J., Kuhlemeier, C., et al. (2012). Cellular force microscopy for in vivo measurements of plant tissue mechanics. Plant Physiol. 158, 1514-1522. doi: 10.1104/pp.111.191460

Sakakibara, K., Nishiyama, T., Sumikawa, N., Kofuji, R., Murata, T., and Hasebe, M. (2003). Involvement of auxin and a homeodomain-leucine zipper I gene in rhizoid development of the moss Physcomitrella patens. Development 130, 4835L-4846. doi: $10.1242 /$ dev.00644

Sapala, A., and Smith, R. S. (2020). "Osmotic Treatment for Quantifying Cell Wall Elasticity in the Sepal of Arabidopsis thaliana," in Plant Stem Cells. Methods in Molecular Biology, Vol. 2094, eds M. Naseem and T. Dandekar (New York, NY: Springer).

Sapala, A., Runions, A., and Smith, R. S. (2019). Mechanics, geometry and genetics of epidermal cell shape regulation: different pieces of the same puzzle. Curr. Opin. Plant Biol. 47, 1-8. doi: 10.1016/j.pbi.2018.07.017

Shani, E., Ben-Gera, H., Shleizer-Burko, S., Burko, Y., Weiss, D., and Ori, N. (2010). Cytokinin regulates compound leaf development in tomato. Plant Cell 22, 3206-3217. doi: 10.1105/tpc.110.078253

Skalák, J., Vercruyssen, L., Claeys, H., Hradilová, J., Černý, M., Novák, O., et al. (2019). Multifaceted activity of cytokinin in leaf development shapes its size and structure in Arabidopsis. Plant J. 97, 805-824. doi: 10.1111/tpj.1 4285

Solly, J. E., Cunniffe, N. J., and Harrison, C. J. (2017). Regional Growth Rate Differences Specified by Apical Notch Activities Regulate Liverwort Thallus Shape. Curr. Biol. 27, 16-26. doi: 10.1016/j.cub.2016.10.056

Spinner, L., Pastuglia, M., Belcram, K., Pegoraro, M., Goussot, M., Bouchez, D., et al. (2010). The function of TONNEAU1 in moss reveals ancient mechanisms of division plane specification and cell elongation in land plants. Development 137, 2733-2742. doi: 10.1242/dev.043810

Thelander, M., Landberg, K., and Sundberg, E. (2018). Auxin-mediated developmental control in the moss Physcomitrella patens. J. Exp. Bot. 69, 277-290. doi: 10.1093/jxb/erx255 
Tomescu, A. M. F. (2009). Megaphylls, microphylls and the evolution of leaf development. Trends Plant Sci. 14, 5-12. doi: 10.1016/j.tplants.2008.10.008

Turchi, L., Baima, S., Morelli, G., and Ruberti, I. (2015). Interplay of HD-Zip II and III transcription factors in auxin-regulated plant development. J. Exp. Bot. 66, 5043-5053. doi: 10.1093/jxb/erv174

van Dop, M., Fiedler, M., Mutte, S., Keijzer, J., Olijslager, L., Albrecht, C., et al. (2020). DIX domain polymerization drives assembly of plant cell polarity complexes. Cell 180, 427.e-439.e. doi: 10.1016/j.cell.2020.01.011

Véron, E., Vernoux, T., and Coudert, Y. (2021). Phyllotaxis from a Single Apical Cell. Trends Plant Sci. 26, 124-131. doi: 10.1016/j.tplants.2020.09.014

Viaene, T., Landberg, K., Thelander, M., Medvecka, E., Pederson, E., Feraru, E., et al. (2014). Directional Auxin Transport Mechanisms in Early Diverging Land Plants. Curr. Biol. 24, 2786-2791. doi: 10.1016/j.cub.2014.09.056

Vieten, A., Sauer, M., Brewer, P. B., and Friml, J. (2007). Molecular and cellular aspects of auxin-transport-mediated development. Trends Plant Sci. 12, 160168. doi: $10.1016 /$ j.tplants.2007.03.006

Vijayan, A., Tofanelli, R., Strauss, S., Cerrone, L., Wolny, A., Strohmeier, J., et al. (2021). A digital 3D reference atlas reveals cellular growth patterns shaping the Arabidopsis ovule. Elife 10:e63262. doi: 10.7554/eLife.63262

Weijers, D., Nemhauser, J., and Yang, Z. (2018). Auxin: small molecule, big impact. J. Exp. Bot. 69, 133-136. doi: 10.1093/jxb/erx463

Whitewoods, C. D., Cammarata, J., Nemec Venza, Z., Sang, S., Crook, A. D., Aoyama, T., et al. (2018). CLAVATA Was a Genetic Novelty for the Morphological Innovation of 3D Growth in Land Plants. Curr. Biol. 28, 2365.e2376.e. doi: $10.1016 /$ j.cub.2018.05.068

Whitewoods, C. D., Goncalves, B., Cheng, J., Cui, M., Kenneway, R., Lee, K., et al. (2020). Evolution of carnivorous traps from planar leaves through simple shifts in gene expression. Science 367, 91-96. doi: 10.1126/science.aay5433
Wolny, A., Cerrone, L., Vijayan, A., Tofanelli, R., Barro, A. V., Louveaux, M., et al. (2020). Accurate and versatile 3D segmentation of plant tissues at cellular resolution. eLife 9:e57613. doi: 10.7554/eLife.57613

Xu, B., Ohtani, M., Yamaguchi, M., Toyooka, K., Wakazaki, M., Sato, M., et al. (2014). Contribution of NAC transcription factors to plant adaptation to land. Science 343, 1505-1508. doi: 10.1126/science.1248417

Yip, H. K., Floyd, S. K., Sakakibara, K., and Bowman, J. L. (2016). Class III HD-Zip activity coordinates leaf development in Physcomitrella patens. Dev. Biol. 419, 184-197. doi: 10.1016/j.ydbio.2016.01.012

Zotz, G., Wilhelm, K., and Becker, A. (2011). Heteroblasty-A Review. Bot. Rev. 77, 109-151. doi: 10.1007/s12229-010-9062-8

Conflict of Interest: The authors declare that the research was conducted in the absence of any commercial or financial relationships that could be construed as a potential conflict of interest.

Publisher's Note: All claims expressed in this article are solely those of the authors and do not necessarily represent those of their affiliated organizations, or those of the publisher, the editors and the reviewers. Any product that may be evaluated in this article, or claim that may be made by its manufacturer, is not guaranteed or endorsed by the publisher.

Copyright $\odot 2021$ Lin, Wang, Coudert and Kierzkowski. This is an open-access article distributed under the terms of the Creative Commons Attribution License (CC BY). The use, distribution or reproduction in other forums is permitted, provided the original author(s) and the copyright owner(s) are credited and that the original publication in this journal is cited, in accordance with accepted academic practice. No use, distribution or reproduction is permitted which does not comply with these terms. 